\title{
Força de tração e mobilização do solo por hastes sulcadoras de semadoras-adubadoras
}

\author{
Carla T. C. Cepik ${ }^{1}$, Carlos R. Trein ${ }^{2}$, Renato Levien², \& 0 smar Conte $^{2}$
}

\begin{abstract}
RESU MO
0 desempenho de semeadoras-adubadoras pode ser influenciado pelos resíduos culturais sobre 0 solo em áreas com semeadura direta. Neste sistema, a utilização de hastes sulcadoras para distribuiçãa de adubo pode minimizar possíveis zonas de compactação. 0 objetivo do trabalho foi avaliar o efeito das variáveis doses de resíduos de culturas de inverno uniformemente distribuídos no solo, profundidades de atuação do sulcador de adubo e número de linhas da semeadora sobre a demanda de tração medida nas hastes, mobilização do solo nos sulcos de semeadura e patinagem dos rodados do trator em Argissolo Vermelho distrófico típico. No inverno foram semeadas aveia preta e aveia preta + nabo forrageiro como culturas antecessoras às de milho e feijão, respectivamente. A força de tração medida nas hastes sulcadoras foi afetada pela profundidade de trabalho na semeadura de milho (3 linhas) e de feijão (5 linhas) e pelas doses de resíduo apenas na de feijão. A mobilização do solo pelos sulcadores de adubo foi influenciada por todas as variáveis estudadas, enquanto a patinagem dos rodados do trator, pelas doses de resíduos e pelo esforço de tração originado da maior profundidade de atuação das hastes e do número de hastes da semeadora.
\end{abstract}

Palavras-chave: semeadura direta, sulcadores, doses de resíduos, patinagem de rodados

\section{Power demand and soil mobilization in fixed shanks of seed drills}

\begin{abstract}
No tillage implies keeping the soil surface covered with crops or crop residues, which might influence planter performance. Using fixed shanks as furrow openers to place fertiliser is an alternative to minimize compaction, as it mobilizes the soil in the sowing line. The aim of this research was to evaluate the effect of different amounts of winter cover crop residues evenly distributed on the soil, the effect of the shanks working depth and quantity of planter lines on power demand, cross sectional furrow area and total volume of soil mobilized in the lines and corresponding wheel slippage in distrophic red Argisol. During winter, black oats and black oats plus turnip were used as cover crops before maize and beans, respectively. Increasing the working depth showed an increase in power demand, as measured directly at the shanks (three lines for maize and five for beans). There was also an effect of residue, increasing power demand on the shanks, but only measurable with the planter operating with three lines in maize sowing. Soil mobilization in the sowing lines was influenced by the amount of residues, the working depths of shank and the quantity of planter lines. Wheel slippage was higher with larger amounts of soil cover residues and when power demand was higher.
\end{abstract}

Key words: no tillage, seed drill, furrow opener, wheel slippage

${ }^{1}$ Ciências Agrárias/U LBRA. Av. Farroupilha, 8001. CEP 92425-900. Canoas, RS. Fone: (51) 3477-9284. E-mail: carlacepik@yahoo.com.br

2 PPG Ciência do Solo/UFRGS. Av. Bento Gonçalves, 7712. CEP 91540-000. Porto Alegre, RS. Fone: (51) 3308-6001. E-mail: trein@ufrgs.br, renatole@ufrgs.br, agroconte@yahoo.com.br 


\section{INTRODUÇÃO}

A utilização da técnica de semeadura direta implica na manutenção dos resíduos culturais sobre o solo, visto que os resíduos podem influenciar o desempenho da operação de semeadura no posicionamento da semente no solo e no condicionamento do microclima ao redor da mesma, afetando a germinação das plantas (Casão Júnior et al., 1992). Em situações nas quais o sulcador atua de forma a deixar o solo descoberto, pode torná-lo vulnerável à invasão de plantas indesejáveis e à ação de agentes erosivos. Desta forma, a quantidade de palha, seu tamanho e posicionamento na superfície do solo, são fatores passíveis de afetar o desenvolvimento e a produtividade de uma cultura. Neste contexto, o desempenho das semeadoras-adubadoras, suas regulagens e operação eficiente, influenciam diretamente na germinação e na emergência das culturas. Muitas áreas afetadas por compactação superficial não necessitariam ser descompactadas ou revolvidas antes da semeadura se as semeadoras-adubadoras fossem reguladas adequadamente, o que resultaria em posicionamento eficiente das sementes e do adubo para uma boa germinação e crescimento das plantas, mesmo em solos com diferentes teores de água (Casão Júnior et al., 2000). Em áreas compactadas ou suscetíveis à compactação, a utilização de hastes sulcadoras para distribuição de adubo deve ser considerada. Além da função de distribuição de adubo, as hastes sulcadoras têm a função de mobilização do solo na linha de semeadura, minimizando possíveis zonas de compactação (Unger \& Kaspar; 1994; Tormena et al., 1998; Abreu et al., 2004; Genro Júnior et al., 2004); entretanto, a profundidade ideal de atuação das hastes sulcadoras ainda é questionada, tanto por produtores como por pesquisadores. A hipótese deste estudo é que maiores quantidades de resíduos culturais na superfície do solo e a atuação das hastes sulcadoras a maiores profundidades aumentam os esforços de tração necessários para a operação de semeadura. Objetivou-se, com este estudo, avaliar um conjunto trator e semeadoraadubadora equipado com três e cinco linhas de semeadura, operando em Argissolo Vermelho distrófico típico, em semeadura direta, com diferentes doses de resíduo sobre a superfície $\left(0,2,3,4,5\right.$ e $\left.6 \mathrm{Mg} \mathrm{ha}^{-1}\right)$ e com hastes sulcadoras de distribuição de adubo atuando em diferentes profundidades de distribuição (0,06 e 0,12 m).

\section{MATERIAL E MÉTODOS}

O estudo foi realizado na Estação Experimental Agronômica da Universidade Federal do Rio Grande do Sul (EEA UFRGS), no Município de Eldorado do Sul, RS. O experimento foi instalado em área com Argissolo Vermelho distrófico típico (EMBRAPA, 1999), unidade de mapeamento São Jerônimo (Brasil, 1973), possuindo 0,20 $\mathrm{kg} \mathrm{kg}^{-1}$ de argila.

A área de instalação do experimento foi utilizada com pecuária durante 15 anos, a partir de 2001 foram implantadas em semeadura direta, as culturas de inverno e verão, conforme a Tabela 1.
Tabela 1. Sucessão de culturas implantadas na área experimental

\begin{tabular}{ccc}
\hline Ano Agrícola & Inverno & Verão \\
2000 & Campo Natural & \\
2001 & Aveia preta & Soja \\
2002 & Aveia preta & Milho \\
2003 & Aveia preta & Soja \\
2004 & Aveia preta e Nabo forrageiro & Feijão \\
\hline
\end{tabular}

O limite de plasticidade desta área experimental é de $0,14 \mathrm{~kg} \mathrm{~kg}^{-1}$ e o de contração é de $0,08 \mathrm{~kg} \mathrm{~kg}^{-1}$ (Cepik et al., 2005). Na semeadura do milho, em 2002, o teor de água no solo foi de $0,14 \mathrm{~kg} \mathrm{~kg}^{-1}$ e, em 2004, por ocasião da semeadura do feijão, foi de $0,17 \mathrm{~kg} \mathrm{~kg}^{-1}$. As culturas implantadas no inverno tiveram a função de fornecer resíduos culturais para cobertura do solo e, sobre estes, foram semeadas as culturas de verão.

Os tratamentos principais foram definidos a partir de doses de resíduos da cultura de inverno sobre a superfície do solo. Empregaram-se seis doses de resíduos: 0, 2, 3, 4, 5 e $6 \mathrm{Mg} \mathrm{ha}^{-1}$. Para obter $0 \mathrm{Mg} \mathrm{ha}^{-1}$ de massa seca nas culturas de inverno, as plantas que emergiram foram dessecadas com herbicida de ação total Roundup ${ }^{\circledR}$ Original (glifosato, $480 \mathrm{~g} \mathrm{~L}^{-1}$ ), na dosagem de $1,5 \mathrm{~L} \mathrm{ha}^{-1}$ de produto comercial. A aplicação do fertilizante mineral foi realizada em duas profundidades nominais (0,06 e 0,12 m), que consistiram nos tratamentos secundários.

A dimensão das parcelas foi de $7 \mathrm{~m}$ de comprimento por $5 \mathrm{~m}$ de largura, divididas em subparcelas de 2,5 m de largura. Mediu-se a demanda de tração das hastes sulcadoras de adubo durante a semeadura direta do milho, em 2002, e do feijão, em 2004, assim como as demais avaliações. Utilizouse uma semeadora-adubadora de precisão, marca Vence Tudo, modelo 11500, montada. Cada linha de semeadura constituiu-se de um disco de corte de palha, de uma haste sulcadora para deposição do fertilizante e discos duplos desencontrados para abertura do sulco onde as sementes foram depositadas a uma profundidade média de 0,05 m.

A haste sulcadora instrumentada utilizada tinha ponteiras com $0,025 \mathrm{~m}$ de largura, ângulo de ataque de $20^{\circ}$ que foram reguladas para a profundidade nominal de 0,06 ou 0,12 m, dependendo do tratamento secundário. A distância entre linhas de semeadura para milho foi de $0,8 \mathrm{~m}$ e, para a semeadura de feijão, de $0,45 \mathrm{~m}$. Usou-se um trator com TDA, marca John Deere, modelo 5600, com potência máxima no motor de 53 kW. A tração dianteira auxiliar não foi acionada nos ensaios. O conjunto trator/semeadora-adubadora operou a velocidade média de $4,5 \mathrm{~km} \mathrm{~h}^{-1}$. Para a medição dos valores de esforço de tração nas hastes foram instalados, no suporte de duas linhas, estensômetros de resistência elétrica capazes de medir a deformação ocorrida no suporte quando em operação. A aquisição de dados foi executada em uma frequência de cinco leituras por segundo o que equivale, considerando-se a velocidade de operação utilizada, a um valor medido e armazenado a cada 0,25 m. Os dados foram armazenados por meio do uso de um datalogger da marca Campbel Scientific, modelo CR23X. Para determinar a área de seção do sulco, utilizou-se um perfilômetro com 0,35 m 
de largura, equipado com varetas espaçadas em $0,01 \mathrm{~m}$ e curso (deslocamento vertical) de $0,30 \mathrm{~m}$. O delineamento experimental utilizado foi o de blocos casualizados, com parcelas subdivididas e seis repetições. As médias dos tratamentos foram comparadas entre si através do teste de análise de médias de Tukey $(\mathrm{P}<0,05)$. As análises estatísticas dos dados de milho e de feijão foram feitas independentemente.

\section{RESULTADOS E DISCUSSÃO}

Os dados serão apresentados conjuntamente para a operação de semeadura com três linhas de semeadura configuradas para milho e com cinco linhas de semeadura configuradas para feijão. Na Tabela 2 se encontram os valores de profundidade máxima do sulco, que foram avaliados utilizando-se o perfilômetro já descrito. Os resultados são apresentados em centímetros, devido à utilização posterior em outros cálculos como, por exemplo, a determinação da força específica $\left(\mathrm{N} \mathrm{cm}^{-1}\right)$.

Não houve diferença significativa entre os resultados em relação às diferentes doses de resíduos culturais. As profundidades nominais de atuação das hastes sulcadoras para distribuição de adubo (0,06 e 0,12 m) não foram atingidas. $\mathrm{Na}$

Tabela 2. Profundidade máxima efetiva dos sulcos (cm), área de solo mobilizado $\left(\mathrm{cm}^{2}\right)$ e volume de solo mobilizado $\left(\mathrm{m}^{3}\right.$ ha-1) pela haste sulcadora de adubo em função de doses de resíduos e número de linhas da semeadora-adubadora

\begin{tabular}{|c|c|c|c|c|c|c|}
\hline \multirow{4}{*}{$\begin{array}{l}\text { Doses de } \\
\text { resíduos } \\
\left(\mathrm{Mg} \mathrm{ha}^{-1}\right)\end{array}$} & \multicolumn{6}{|c|}{ Número de linhas de semeadura } \\
\hline & \multicolumn{3}{|c|}{3 linhas } & \multicolumn{3}{|c|}{5 linhas } \\
\hline & \multicolumn{6}{|c|}{ Profundidade de atuação da haste (m) } \\
\hline & 0,06 & 0,12 & Média & 0,06 & 0,12 & Média \\
\hline \multicolumn{7}{|c|}{ Profundidade máxima efetiva dos sulcos (cm) } \\
\hline 0 & 6,7 & 11,6 & $9,1 \mathrm{a}$ & 6,8 & 11,5 & $9,2 \mathrm{a}$ \\
\hline 2 & 6,7 & 11,5 & $9,1 \mathrm{a}$ & 6,9 & 11,4 & $9,2 \mathrm{a}$ \\
\hline 3 & 6,4 & 11,7 & $9,0 \mathrm{a}$ & 7,1 & 11,7 & $9,4 \mathrm{a}$ \\
\hline 4 & 6,6 & 11,5 & $9,0 \mathrm{a}$ & 7,0 & 11,4 & $9,2 \mathrm{a}$ \\
\hline 5 & 6,3 & 11,4 & $8,8 \mathrm{a}$ & 7,6 & 11,2 & $9,4 \mathrm{a}$ \\
\hline 6 & 6,1 & 11,2 & $8,6 \mathrm{a}$ & 7,1 & 10,6 & $8,9 \mathrm{a}$ \\
\hline Média & $6,5 \mathrm{~A}$ & $11,5 \mathrm{~B}$ & 9,0 & $7,1 \mathrm{~A}$ & $11,3 \mathrm{~B}$ & 9,2 \\
\hline \multicolumn{7}{|c|}{ Área de solo mobilizado $\left(\mathrm{cm}^{2}\right)$} \\
\hline 0 & 50,9 & 63,5 & $57,2 \mathrm{a}$ & $50,7 \mathrm{Aa}$ & $53,7 \mathrm{Aa}$ & 52,2 \\
\hline 2 & 53,9 & 63,2 & $58,5 \mathrm{a}$ & $53,0 \mathrm{Aa}$ & $59,8 \mathrm{Aab}$ & 56,4 \\
\hline 3 & 52,7 & 63,9 & $58,3 \mathrm{ab}$ & $55,0 \mathrm{Aa}$ & 63,3 Aabc & 59,2 \\
\hline 4 & 55,5 & 64,7 & 60,1 b & $54,5 \mathrm{Aa}$ & $70,6 \mathrm{Bbc}$ & 62,6 \\
\hline 5 & 53,4 & 66,1 & $59,7 \mathrm{ab}$ & $56,2 \mathrm{Aa}$ & 77,1 Bbd & 66,7 \\
\hline 6 & 56,2 & 67,8 & $62,0 \mathrm{c}$ & $55,2 \mathrm{Aa}$ & $87,7 \mathrm{Bd}$ & 71,5 \\
\hline Média & $53,8 \mathrm{~A}$ & 64,9 B & 59,3 & 54,1 & 68,7 & 61,4 \\
\hline \multicolumn{7}{|c|}{ Volume de solo mobilizado $\left(\mathrm{m}^{3} \mathrm{ha}^{-1}\right)$} \\
\hline 0 & 63,6 & 79,4 & $71,5 \mathrm{a}$ & 126,8 & 134,3 & $130,6 \mathrm{a}$ \\
\hline 2 & 67,4 & 79,0 & $73,2 \mathrm{a}$ & 132,5 & 149,5 & $141,0 \mathrm{a}$ \\
\hline 3 & 65,9 & 79,9 & $72,9 \mathrm{ab}$ & 137,5 & 158,3 & $147,9 \mathrm{ab}$ \\
\hline 4 & 69,4 & 80,9 & $75,1 \mathrm{~b}$ & 136,3 & 176,5 & $156,4 \mathrm{~b}$ \\
\hline 5 & 66,7 & 82,6 & 74,7 bc & 140,5 & 192,8 & $166,7 \mathrm{bc}$ \\
\hline 6 & 70,3 & 84,7 & 77,5 c & 138,0 & 219,3 & $178,7 \mathrm{c}$ \\
\hline Média & $67,2 \mathrm{~A}$ & $81,1 \mathrm{~B}$ & 74,2 & $135,3 \mathrm{~A}$ & $171,8 \mathrm{~B}$ & 153,6 \\
\hline
\end{tabular}

Médias seguidas de mesma letra minúscula nas colunas e maiúscula na linha não diferem entre si $(P<0,05 \%)$ menor profundidade $(0,06 \mathrm{~m})$, os valores excederam o pretendido com a regulagem. Já na profundidade de $0,12 \mathrm{~m}$, na média, a profundidade alcançou valores na ordem de $0,115 \mathrm{~m}$ para a operação de semeadura de milho (3 linhas) e 0,113 m na operação de semeadura do feijão (5 linhas). Casão Júnior et al. (2000), comparando dez modelos de semeadoras-adubadoras, todas equipadas com hastes sulcadoras de adubo, constataram a dificuldade geral de regulagem da profundidade do sulcador de adubo. As máquinas trabalharam entre 0,129 e $0,199 \mathrm{~m}$, valores acima dos $0,10 \mathrm{~m}$ requeridos no teste. Os autores recomendaram aos fabricantes o desenvolvimento de um dispositivo para a manutenção da profundidade de atuação da haste sulcadora de adubo. Na Tabela 2 se encontram os dados da área da seção transversal dos sulcos, quantificados logo após a operação de semeadura do milho e do feijão.

Na operação de semeadura do milho, através de semeadora com três linhas, se verifica que um aumento de $5 \mathrm{~cm}$ na profundidade de atuação do sulcador de adubo (0,065 para 0,115 m) implicou em 20,6\% de aumento na área de solo mobilizada. Os resultados também mostram que a mobilização do solo efetuada pelo sulcador de adubo da semeadoraadubadora foi influenciada pelas doses de resíduo nas quantidades de 0 e $6 \mathrm{Mg}_{\text {ha-1 }}$, na média das profundidades testadas sendo maior a área de solo mobilizado com doses maiores de resíduos culturais devido, provavelmente, à maior quantidade de raízes no tratamento com maior dose de resíduo, influenciando o sulcamento do solo. Já na semeadura do feijão, com 5 linhas espaçadas em 0,4 m, houve interação significativa entre as doses de resíduos, mas somente apresentaram diferença significativa as doses 0 e $6 \mathrm{Mg} \mathrm{ha}^{-1}$. Ocorreu diferença significativa entre as profundidades de atuação do sulcador de adubo a partir de $4 \mathrm{Mg} \mathrm{ha}^{-1}$.

Na Tabela 2 se encontram os dados calculados de volume de solo mobilizado. Nas duas operações de semeadura avaliadas foi notória a diferença entre as profundidades de atuação das hastes sulcadoras quanto ao volume de solo mobilizado. Considerando o espaçamento de $0,80 \mathrm{~m}$ entre linhas de semeadura (três linhas) tem-se que, quando a profundidade de atuação passou de 0,065 para $0,115 \mathrm{~m}$, houve um aumento de mobilização de solo, da ordem de 13,9 $\mathrm{m}^{3} \mathrm{ha}^{-1}$, representando um incremento de $20 \%$ em relação ao solo mobilizado com a haste a $0,065 \mathrm{~m}$ de profundidade. Utilizando-se cinco linhas, o incremento de solo mobilizado com o aumento da profundidade de atuação dos sulcadores (de 0,071 para $0,113 \mathrm{~m}$ ) foi de $36,5 \mathrm{~m}^{3} \mathrm{ha}^{-1}$, representando, neste caso, um aumento de $27 \%$.

A quantidade de resíduos teve importância fundamental sobre o solo mobilizado, sendo que maiores quantidades de resíduo resultaram em maiores quantidades de solo mobilizado. Com o solo descoberto $\left(0 \mathrm{Mg} \mathrm{ha}^{-1}\right)$, três sulcadores (espaçados $0,80 \mathrm{~m}$ ) mobilizaram $71,5 \mathrm{~m}^{3}$ em média e, com $6 \mathrm{Mg} \mathrm{ha}^{-1}$ de resíduos sobre o solo, foram mobilizados 77,5 $\mathrm{m}^{3}$. Com cinco linhas de semeadura (espaçadas 0,40 m) foram mobilizados $131 \mathrm{~m}^{3}$ de solo na ausência de cobertura e $179 \mathrm{~m}^{3}$ quando com $6 \mathrm{Mg} \mathrm{ha}^{-1}$ de resíduos culturais. Na Tabela 3 se encontram os valores de demanda de tração medidos na haste sulcadora instrumentada. Os valores obtidos nos testes não 
Tabela 3. Força de tração ( $N)$, força de tração específica $\left(\mathrm{N} \mathrm{cm}^{-2}\right)$ e patinagem das rodas tratórias $\left(\mathrm{m} \mathrm{m}^{-1}\right.$ ) na haste sulcadora de adubo em função de doses de resíduos de inverno e profundidades de atuação do sulcador de adubo

\begin{tabular}{|c|c|c|c|c|c|c|}
\hline \multirow{4}{*}{$\begin{array}{l}\text { Doses de } \\
\text { resíduos } \\
\left(\mathrm{Mg} \mathrm{ha}^{-1}\right)\end{array}$} & \multicolumn{6}{|c|}{ Número de linhas de semeadura } \\
\hline & \multicolumn{3}{|c|}{3 linhas } & \multicolumn{3}{|c|}{5 linhas } \\
\hline & \multicolumn{6}{|c|}{ Profundidade de atuação da haste } \\
\hline & $0,065 \mathrm{~m}$ & $0,115 \mathrm{~m}$ & Média & $0,071 \mathrm{~m}$ & $0,113 \mathrm{~m}$ & Média \\
\hline \multicolumn{7}{|c|}{ Força de tração $(\mathrm{N})$} \\
\hline 0 & 772 & 1313 & $1043 a b$ & 1030 & 1311 & $1171 \mathrm{a}$ \\
\hline 2 & 783 & 1204 & $994 \mathrm{ab}$ & 980 & 1323 & $1152 \mathrm{a}$ \\
\hline 3 & 704 & 1179 & $942 \mathrm{a}$ & 1006 & 1314 & $1160 \mathrm{a}$ \\
\hline 4 & 829 & 1250 & $1040 a b$ & 1001 & 1393 & $1197 \mathrm{a}$ \\
\hline 5 & 870 & 1251 & $1061 a b$ & 944 & 1252 & $1098 \mathrm{a}$ \\
\hline 6 & 911 & 1264 & $1088 \mathrm{~b}$ & 947 & 1244 & $1096 \mathrm{a}$ \\
\hline Média & $812 \mathrm{~A}$ & $1244 \mathrm{~B}$ & 1028 & $985 \mathrm{~A}$ & $1306 \mathrm{~B}$ & 1146 \\
\hline \multicolumn{7}{|c|}{ Força de tração específica $\left(\mathrm{N} \mathrm{cm}^{-2}\right)$} \\
\hline 0 & 15,2 & 20,7 & 17,9 a & 20,3 & 24,4 & 22,4 a \\
\hline 2 & 14,5 & 19,1 & $16,8 \mathrm{a}$ & 18,5 & 22,2 & 20,4 a \\
\hline 3 & 13,4 & 18,5 & $15,9 \mathrm{a}$ & 18,3 & 20,8 & $19,5 \mathrm{a}$ \\
\hline 4 & 14,9 & 19,3 & $17,1 \mathrm{a}$ & 18,4 & 19,7 & $19,0 \mathrm{a}$ \\
\hline 5 & 16,3 & 18,9 & $17,6 \mathrm{a}$ & 16,8 & 16,2 & $16,5 \mathrm{~b}$ \\
\hline 6 & 16,2 & 18,6 & $17,4 \mathrm{a}$ & 17,2 & 14,2 & $15,7 \mathrm{~b}$ \\
\hline Média & $15,1 \mathrm{~A}$ & $19,2 \mathrm{~B}$ & 17,1 & $18,2 \mathrm{~A}$ & $19,0 \mathrm{~A}$ & 18,7 \\
\hline \multicolumn{7}{|c|}{ Patinagem das rodas tratórias $\left(\mathrm{m} \mathrm{m}^{-1}\right)$} \\
\hline 0 & 0,05 & 0,06 & $0,05 \mathrm{a}$ & 0,08 & 0,13 & $0,11 \mathrm{a}$ \\
\hline 2 & 0,05 & 0,06 & $0,05 \mathrm{a}$ & 0,09 & 0,16 & $0,13 a b$ \\
\hline 3 & 0,05 & 0,07 & $0,06 \mathrm{a}$ & 0,13 & 0,17 & $0,15 \mathrm{bc}$ \\
\hline 4 & 0,05 & 0,08 & $0,06 \mathrm{a}$ & 0,14 & 0,18 & $0,16 \mathrm{~cd}$ \\
\hline 5 & 0,06 & 0,07 & $0,06 \mathrm{a}$ & 0,18 & 0,20 & $0,19 \mathrm{de}$ \\
\hline 6 & 0,04 & 0,07 & $0,06 \mathrm{a}$ & 0,19 & 0,23 & $0,21 \mathrm{e}$ \\
\hline Média & $0,05 \mathrm{~A}$ & $0,07 \mathrm{~B}$ & 0,06 & $0,14 \mathrm{~A}$ & $0,18 \mathrm{~B}$ & 0,16 \\
\hline
\end{tabular}

Médias seguidas de mesma letra minúscula nas colunas e maiúscula na linha não diferem entre si $(P<0,05 \%)$

excederam os recomendados pela ASAE (2003) que têm como valor de referência para projetos, $3400 \mathrm{~N}$ de esforço demandado na barra de tração.

Na operação com três linhas de semeadura ocorreu diferença significativa nos valores de demanda de tração em relação à profundidade de atuação das hastes, sendo 53,2\% superior na profundidade $0,115 \mathrm{~m}$, em relação à de $0,065 \mathrm{~m}$. Silveira et al. (2005) também constataram aumento na demanda de tração com aumento da profundidade de semeadura com semeadoras de fluxo contínuo. Comparando-se com a quantidade de solo mobilizada, nota-se um aumento de $20 \%$ apenas na mesma situação. Já nas doses de resíduos de aveia preta, somente apresentaram diferença significativa os tratamentos 3 e $6 \mathrm{Mg} \mathrm{ha}^{-1}$.

Com cinco linhas de semeadura, a demanda de tração na menor profundidade foi de $985 \mathrm{~N}$ e, na profundidade maior, chegou a $1306 \mathrm{~N}$, caso em que o aumento na demanda de tração foi de 321 N, ou seja, de 32,6\%. Neste caso, e se comparando com o aumento da área mobilizada, verifica-se que esta aumentou em $27 \%$. Não houve diferença significativa nos valores de força demandada nas hastes nas diferentes doses de resíduos na operação com 5 linhas de semeadura, caso em que se pode afirmar que não houve influência da quantidade de resíduos sobre a demanda de potência pelo sulcador. Em trabalho efetuado anteriormente, Cepik et al. (2005) avaliaram a demanda de força de tração na haste sulcadora de adubo em semeadura de soja sobre campo nativo e observou valores médios de $614 \mathrm{~N}(0,06 \mathrm{~m})$ e $1409 \mathrm{~N}$ (0,12 m), neste mesmo solo, na consistência friável. Esta menor diferença entre as duas profundidades pode ser atribuída ao arranjo estrutural do solo da área, visto que a cultura foi implantada diretamente sobre campo nativo dessecado. Bordignon (2005), em Latossolo Vermelho Distroférrico (> 60\% argila), avaliou o esforço horizontal em hastes sulcadoras e obteve 485, 1082 e $2566 \mathrm{~N}$ nas profundidades de atuação das hastes de 0,08, 0,13 e 0,18 m. A velocidade de operação do conjunto foi de $6 \mathrm{~km} \mathrm{~h}^{-1}$.

Conte et al. (2007) avaliaram, em área de integração lavoura-pecuária, o esforço de tração demandado por hastes sulcadoras na operação de semeadura direta da soja em áreas com diferentes intensidades de pastejo e concluiu que as maiores demandas de tração ocorreram nos tratamentos mais pastejados, demonstrando o impacto da presença dos animais. Os valores de esforço de tração na maior profundidade de atuação $(0,15 \mathrm{~m})$ foram de $3840 \mathrm{~N}$ na área sem pastejo até 4970 N na área com o pastejo mais intensivo. Ressalta-se que a haste usada tinha formato diferente da utilizada no presente trabalho. Siqueira et al. (2001) obtiveram valores de força de tração de 1376 e 2201 N, comparando treze modelos de hastes, atuando em velocidade média de $5,5 \mathrm{~km} \mathrm{~h}^{-1}$. A profundidade de atuação dos sulcadores foi de 0,117 a 0,133 m. A força de tração específica se refere à força demandada na haste sulcadora de adubo da semeadora-adubadora relacionada à área da seção transversal do sulco mobilizado pela mesma.

Na Tabela 3 são apresentados os dados de força específica avaliados nos anos agrícolas de 2002 (3 linhas) e 2004 (5 linhas). Na operação de semeadura utilizando-se três linhas, as diferentes doses de resíduos culturais de inverno não afetaram significativamente a força de tração específica. No entanto, as diferentes profundidades de atuação das hastes provocaram diferença significativa na força de tração. As diferentes doses de resíduo apresentaram diferenças significativas na força de tração específica na operação de semeadura utilizando-se cinco linhas. Este efeito pode ter sido devido a uma pequena diferença no teor de água no solo nos tratamentos com maior dose de resíduos. Para que ocorra tração em solos agrícolas é necessário que também ocorra patinagem, porém ultrapassando-se certo limite, pode haver perda de aderência dos rodados com o solo e redução de tração (Lanças \& Upadhyaya, 1997).

Na Tabela 3 são apresentados os valores de patinagem das rodas tratórias obtidos no momento das operações de semeadura. ASAE (1989) recomenda, para obtenção de máxima eficiência de tração, patinagem de 0,08 a $0,10 \mathrm{~m} \mathrm{~m}^{-1}$ em solos não mobilizados e de 0,11 a $0,13 \mathrm{~m} \mathrm{~m}^{-1}$ em solos mobilizados. Na operação de semeadura com 5 linhas esta referência foi excedida. Na operação de semeadura em que foram utilizadas 3 linhas montadas, a quantidade de resíduos culturais sobre o solo não afetou o desempenho do trator, no que diz respeito à patinagem, quando aplicado o teste de médias. Com o uso de 5 linhas e, portanto, uma demanda 
de potência maior na barra de tração, o efeito da cobertura é claramente visível. A patinagem aumenta à medida que aumenta a quantidade de resíduos sobre o solo, efeito que pode ser atribuído ao contato deficiente do pneu com o solo, uma vez que boa parte da palha era composta de fragmentos não ancorados e, portanto, passíveis de fácil remoção pelo pneu.

A operação de semeadura com três hastes sulcadoras a 0,115 m de profundidade resultou em aumento de 34\% na patinagem do trator, comparada com os valores de patinagem quando operou a $0,065 \mathrm{~m}$, corroborando com resultados obtidos por Mercante et al. (2005). Mesmo assim, os valores de patinagem ficaram dentro do limite aceitável para tratores $4 \times 2$ com TDA. Trabalhando com cinco hastes a 0,113 m de profundidade de atuação também houve aumento de patinagem, da ordem de $29 \%$, ou seja, passou de 0,14 para $0,18 \mathrm{~m} \mathrm{~m}^{-1}$. Em ambos os casos, a patinagem está acima do recomendado pela literatura técnica, e dessa forma, trabalhando-se com maior número de linhas, seria necessário trabalhar com a TDA do trator acionada.

Fey et al. (2002) avaliaram a patinagem dos rodados tratórios de um trator 4 × 2 tracionando uma semeadora-adubadora em lavoura conduzida em semeadura direta com diferentes doses de resíduos culturais e concluíram que os menores valores de patinagem $\left(0,067 \mathrm{~m} \mathrm{~m}^{-1}\right)$ ocorreram nas áreas com menores doses de cobertura do solo. Herzog et al. (2004) também evidenciaram esta diferença em relação às profundidades de atuação das hastes sulcadoras e entre doses de resíduos sobre o solo, porém na cultura da soja e com a semeadora operando com 5 linhas espaçadas em 0,45 m. A Figura 1 mostra a correlação entre a patinagem e as diferentes doses de resíduo cultural utilizado. Na operação de semeadura com cinco linhas a correlação elevada indica que doses elevadas de resíduo no solo aumentam a patinagem devido, provavelmente, ao comprometimento do contato pneu-solo. Os valores de patinagem dos rodados do trator operando com semeadora de 5 linhas foram excedidos a partir de $3 \mathrm{Mg} \mathrm{ha}^{-1}$ na menor profundidade de atuação $(0,071 \mathrm{~m})$. Na maior profundidade $(0,113 \mathrm{~m})$, estes valores foram excedidos em todas as doses de resíduo, segundo ASAE (1989).

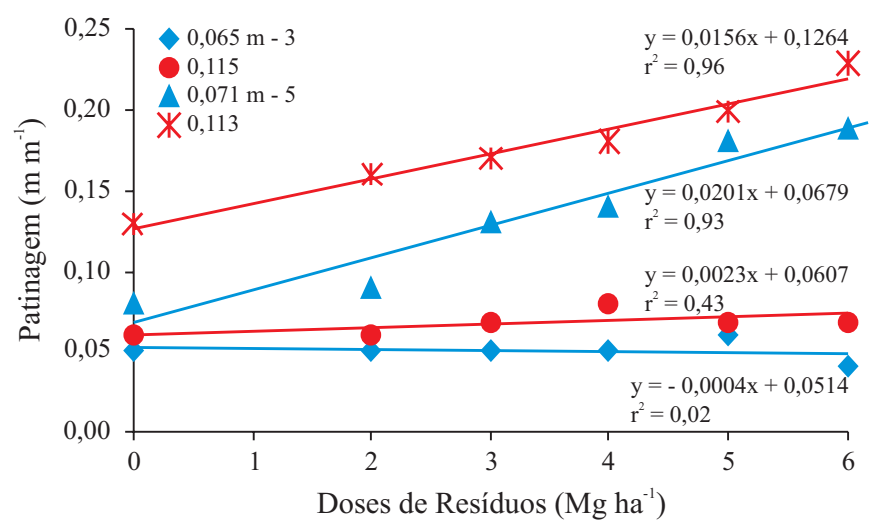

Figura 1. Relação entre doses de resíduo e valores de patinagem dos rodados do trator, nas duas profundidades efetivas da haste sulcadora de adubo, com 3 e 5 linhas de semeadura

\section{CONCLUSÕES}

1. A demanda de tração nas hastes sulcadoras foi afetada pela variação da profundidade, na operação de semeadura, utilizando-se três linhas e cinco linhas de semeadura.

2. A força de tração foi afetada pelas diferentes doses de resíduo na operação com três linhas de semeadura, apresentando valores entre 942 N e 1088 N. Já na operação com cinco linhas utilizando-se a análise das médias, não houve diferença significativa entre as doses de resíduos.

3. A mobilização do solo avaliada nos tratamentos principais (doses de resíduos) e secundários (profundidade de atuação das hastes) apresentou diferenças de volume de solo mobilizado, tanto na operação de semeadura com três linhas, como na feita com cinco linhas de semeadura.

4. A patinagem dos rodados tratórios do trator, avaliada na operação de semeadura com três linhas, apresentou diferenças significativas somente na maior profundidade de atuação das hastes, não sendo influenciada pelas doses de resíduo. Com 5 linhas e sem uso da TDA, os valores obtidos ficaram acima dos recomendados pela literatura.

\section{LITERATURA CITADA}

Abreu, S. L.; Reichert, J. M.; Reinert D. J. Escarificação mecânica e biológica para a redução da compactação em Argissolo Franco-Arenoso sob plantio direto. Revista Brasileira de Ciência do Solo, v.28, n.3, p.519-531, 2004.

ASAE - American Society of Agricultural Engineers. Agricultural tractor test code. In: ASAE standards 1989: Standards engineering practices data. St. Joseph: ASAE, 1989. 5p.

ASAE - American Society of Agricultural Engineers. Agricultural machinery management data. In: ASAE standards 2003: Standards engineering practices data. St. Joseph: ASAE, 2003. 5p.

Bordignon, J. Projeto, construção e desenvolvimento de transdutores para medição de esforços em semeadoras-adubadoras. Porto Alegre: UFRGS, 2005. 122p.

Brasil. Ministério da Agricultura. Departamento Nacional de Pesquisa Agropecuária. Divisão de Pesquisa Pedológica. Levantamento de reconhecimento dos solos do Estado Rio Grande do Sul. Recife: IPEAS, 1973. 431p. Boletim técnico, 30.

Casão Júnior, R.; Henklain, J. C.; Ladeira, A. S.; Moreno, E. C. Efeito de diferentes implementos na resistência a tração e qualidade de preparo do solo (Latossolo Roxo). In: Congresso Brasileiro de Engenharia Agrícola, 20, 1992, Londrina. Anais... Londrina: SBEA/IAPAR, 1992. p.847-868.

Casão Júnior, R.; Siqueira, R.; Araújo, A.G.; Ralisch, R. Dinâmica de semeadoras-adubadoras diretas em Primeiro de Maio - PR. Londrina: IAPAR, 2000. 14p. Boletim Técnico

Cepik, C. T. C.; Trein, C. R.; Levien, R. Força de tração e volume de solo mobilizado por haste sulcadora em semeadura direta sobre campo nativo, em função do teor de água, profundidade e velocidade de operação. Engenharia Agrícola, v.25, n.2, p.447-457, 2005. 
Conte, O.; Levien, R.; Trein, C. R.; Cepik, C. T. C.; Debiasi, H. Demanda de tração em haste sulcadora na integração lavourapecuária com diferentes pressões de pastejo e sua relação com o estado de compactação do solo. Engenharia Agrícola, v.27, n.1, p.220-228, 2007.

EMBRAPA - Empresa Brasileira de Pesquisa Agropecuária. Sistema Brasileiro de Classificação de Solos. Brasília: Embrapa Produção de Informação, 1999. 412p.

Fey, E.; Seidel, G. O.; Verona, M. M.; Erig, P. R.; Fey, A. Desempenho de uma semeadora sob culturas vegetais épocas de dessecação em sistema de semeadura sob a palha. In: Congresso Brasileiro de Engenharia Agrícola, 31, 2002, Salvador. Anais... Salvador: SBEA, 2002. CD-Rom

Genro Júnior, S. A.; Reinert, D. J.; Reichert, J. M. Variabilidade temporal da resistência à penetração de um Latossolo argiloso sob semeadura direta com rotação de culturas. Revista Brasileira de Ciência do Solo, v.28, n.3, p.477-484, 2004.

Herzog, R. L. da S.; Levien, R.; Trein, C. R. Produtividade de soja em semeadura direta influenciada por profundidade do sulcador de adubo e doses de resíduo em sistema irrigado e não irrigado. Engenharia Agrícola, v.24, n.3, p.771-780, 2004.
Lanças, K. P.; Upadhyaya, S. K. Pneus radiais para tratores: guia para seleção correta da pressão de inflação. Botucatu: FCA/ UNESP, 1997. 33p. Boletim Técnico, n.1.

Mercante, E.; Silva, S. L.; Modolo, J.; Silveira, J. C. M. Demanda energética e distribuição de sementes de milho em função da velocidade de duas semeadoras. Revista Brasileira de Engenharia Agrícola e Ambiental, v.9, n.3, p.424-428, 2005.

Silveira, J. C. M.; Modolo, A. J.; Silva, S. L.; Gabriel Filho, A. Força de tração e potência de uma semeadora em duas velocidades de deslocamento e duas profundidades de deposição de sementes. Revista Brasileira de Engenharia Agrícola e Ambiental, v.9, n.1, p.125-128, 2005.

Siqueira, R.; Casão Júnior R.; Ralisch, R.; Araújo, A.G. Variabilidade da demanda energética de hastes sulcadoras de semeadoras-adubadoras diretas. In: Congresso Brasileiro de Engenharia Agrícola, 30, 2001, Foz do Iguaçu. Anais... Foz do Iguaçu: SBEA, 2001. CD-Rom.

Tormena, C. A.; Roloff, G.; Sá, J. C. M. Propriedades físicas do solo sob plantio direto influenciadas por calagem, preparo inicial e tráfego. Revista Brasileira de Ciência do Solo, v.22, n.2, p.301-309, 1998.

Unger, P. W.; Kaspar, T. C. Soil compaction and root growth: A review. Agronomy Journal, v.86, p.759-766, 1994. 